\title{
TOWARDS A RELATIONAL VIEW ON INDUSTRIAL LOCATION THEORY
}

\author{
Dr. Frank Witlox
}

Department of Transport and Spatial Economics, University of Antwerp (UFSIA), Prinsstraat

13, B-2000 Antwerpen

E-mail:frank.witlox@ufsia.ac.be

\section{INTRODUCTION}

Over the years, several theories of industrial location and various methodological approaches to modelling site selection behaviour have been developed that aim at providing the best possible explanation for the observed spatial distribution of economic activities. For instance, classical approaches to location theory have brought a first insight into the goals and purposes of industrial location decision-making, whereby a number of these explanations was based on existing economic principles such as cost minimization, market area maximization and profit maximization. Neo-classical theories spatially extended and reformulated a number of classical ideas. In doing so, linkages were made to other existing theories in the field of economics, international trade, and land-use. The overall result of this interdisciplinary approach was the development of a more general approach to location theory.

From the viewpoint of the behavioural approach to the problem of industrial location, the need to incorporate the motives, preferences and attitudes of the entrepreneur into the explanations of the changing patterns of economic activity was initially highlighted. The notion of optimal or best location site was replaced with a satisfying or suitable location. Furthermore, at the end of the 1960s, a paradigmatic shift could be noted from abstract models, based on 
assumptions of optimizing objectives, towards the observation of actual location practice, supported by case-studies. Quantitative methods (e.g. random utility modelling) were advanced to elicit from entrepreneurs the considerations and determinants relevant to explain location choice behaviour. While the behavioural approach emphasized the importance of freedom of choice, the structuralist approach stressed the fact that locational behaviour is constrained by wider social, historical, political, and economic-related processes. As such, the effects of the socalled "superstructure" were not to be minimized because the location problem of an economic activity could not be properly understood in isolation from its wider socio-economic and technological context.

Notwithstanding these developments in location theory, the current relevant literature suggests that neither extreme behaviouralism nor radical structuralism can be used as the exclusive methodological approach to analyze industrial location. Instead, a more eclectic approach to site selection, which draws upon different theoretical perspectives and avoids the excesses of overstatement which characterized the largely monocausal theories that have classical, neo-classical, behavioural or structural origins is advocated (Hamilton and Linge, 1983, p. 5). This "integrated" approach accentuates the relevance of activity-related behaviour, and also takes into account structural constraints. It also induces an alternative theoretical approach towards defining and modelling locational choice behaviour and site selection. This is to say that it is the interactive result of the requirements generated by an economic activity and the properties characterizing the choice alternatives that define whether a potential location site is suitable or not. As a result, an approach of matching requirements and properties can be followed when dealing with site selection problems. Such an approach would be relevant not only for the analyst, but also for the urban or regional planner, whose responsibility it is to provide land which meets the specific requirements of potential managerial segments, in line with the general profile and mission of the specific city or region. 
Similarly, the significance of locational properties or spatial production factors follows from the interaction of location and economic activity. The activity-specific influence of location factors is easily illustrated in that a location site nearby a port may be suitable for those companies which, e.g., rely heavily upon overseas shipment of goods, use water in their production processes, or have to discharge waste water, but totally unsuitable or non-essential for certain other activities. Consequently, the relevance of a location factor like, e.g., easy access to port facilities depends upon the specific context within which it has to be evaluated. It also means that no single locational property by itself is capable of generating site suitability because there is nothing inherent in a locational property that turns it into a necessary condition under which the location can serve as a suitable site for production.

In this article, the main principles and modelling problems of dealing with the notion of site suitability and selection are examined. It involves a critical assessment of the existing location theory and modelling approaches in order to delineate and enlighten the relational context of the site selection problem. In particular, the following aspects will be discussed. First, the usefulness of the existing location theory with respect to defining the concept of site suitability will be highlighted. Various approaches, such as the (neo)classical location theory, the behavioural approach and the structural approach are briefly discussed. Next, the actual problem of modelling the concept of site suitability as a matching process is discussed from a location theoretical point of view. Following this discussion, the major requirements for location theorybuilding are formulated. Finally, a methodological toolbox is offered which allows one to model industrial location problems as a matching problem. The article ends with a summary of the main conclusions.

\section{DEFINING SITE SUITABILITY IN LOCATION THEORY}


In the theory of industrial location, the notion of site suitability is not distinctly determined. It is defined in guarded terms in different ways, sometimes based on a more mathematical approach, sometimes on a purely behavioural-cognitive one. However, seldom the definition of the concept of site suitability is in accordance with the interpretation put forward in the present article: i.e., site suitability should be defined as an interactive process of linking organizational production requirements with locational properties.

In accordance with the predominant methodological paradigm, different interpretations and definitions of the concept of site suitability have been put forward. In the classical (Launhardt, 1882; Weber, 1909) and "early" neo-classical location theory (Greenhut, 1956; Isard, 1956), site suitability is not really an issue since it is implicitly assumed. Site suitability is simply equivalent to the calculated zones and areas of production within which economic viability is guaranteed. All locations within these spatial margins or regions of profitability are considered "suitable", and thus defined accordingly (Rawstron, 1958; Smith, 1966).

In more behavioural approaches (Dicken, 1971; Hamilton, 1974; Townroe, 1975), a much more inductive kind of analysis is followed, based on empirical similarities and statistical associations. Particular attention is given to how entrepreneurs evaluate the regional or local characteristics of places in relation to their stated goals. It is realized that decision-makers not only behave according to certain regularities and in a stimulus-response framework, but also perceive their own situation on the basis of which they make decisions. As such, the locational requirements of the actor are related to the attributes characterizing the location site. This relationship is measured by means of a series of scores on a number of psychological constructs. Note that these constructs fulfil a so-called intermediate function between the actor and his or her environmental cognition. Approaches such as revealed preference modelling, decompositional multi-attribute modelling and the analytical behavioural studies in geography and urban planning fit into this approach. Although, it is important to take account of attitudes and preferences in 
defining site suitability, it should be clear that a number of structural, behaviour-limiting constraints should be evaluated as well. In this respect, it was argued that the behavioural approach to location theory somehow falls short of achieving this particular goal.

By contrast, the structural approach (Massey, 1973; Boddy, 1987) argues that, in order to understand the recent shifts in the location of an industry, it is necessary to examine the recent changes in both the industry's production requirements and its wider geographical environment. The reason is that different firms in different sectors will respond in different ways depending on the actual circumstances. Note that this assertion of site suitability is somewhat in line with the definition put forward in this article. After all, what is advocated here is an approach in which the relations between the individual decision-maker (i.e. a company) and the constraints of superstructure in which this decision-maker behaves, must be integrated. Site suitability is defined as the outcome of the changing relationship between the requirements of private production for profit and the existing spatial surface. If, on this level, a mismatch occurs, an imbalance in the degree of attractiveness or suitability of a particular area to the dominant form of economic activity is the result, leading to regional inequality. This notion has some important implications, not only for the location theory in general, but also for the development of locational decision models in particular. Also, the point made here does go beyond the earlier criticism of structuralism on the behavioural approach to location theory. It is argued that not only must macro-scale patterns and structures (available technology, spatial division of labour, etc.) be included in theories of locational decision-making, but the relationships between an activity and its environment should also be emphasized. Note also that the concepts of spatial or regional (in)equality and locational suitability, as advanced in the structural approach, explicitly refer to the functionality of location sites for locating different activities based on the interaction between empirical characteristics and the strategies, and properties of the economic activity. The point, however, that the structural approach somehow overstresses the importance of the 
superstructure, and falls short of adequately dealing with the motivational and managerial attitude of decision-makers makes it a less acceptable theory to take as point of departure.

The critique levelled against both the behavioural and structural approaches to location theory opened up the field for the development of alternative approaches. Several authors (Eyles, 1981; Johnston, 1986; Lambooy, 1986; Healey and Ilbery, 1990; Reitsma, 1990; Walmsley and Lewis, 1993) advocated a theory that acknowledges the existence of a balance between choice and constraint. It should recognize an understanding of the reciprocal relationship between behaviour and structure, and be aware of the complex ways in which micro-scale activity (e.g. individual or entrepreneurial decisions) can lead to macro-scale patterns (e.g. the overall geographical context within which behaviour is conducted). Clearly, what is called for is an approach to defining site suitability that combines the best of both worlds. In other words, no extreme behaviouralism or radical structuralism can be used as the exclusive methodological approach to analyze industrial location and define a concept like site suitability as a matching problem. Instead, an integrated approach should be advocated which draws upon different theoretical perspectives of industrial geography and planning (Healey and Ilbery, 1990, p. 30). Such an integrated approach should define the concept of site suitability as a matching process whereby actor requirements and property attributes and conditions are being directly related. As such, attributes are directly and explicitly related to the actions by means of decision rules or heuristics whereby no intermediate or underlying measurement scale is needed.

In the literature, various names have been suggested to refer to an integrated or a more eclectic approach. In this respect, Timmermans and van der Heijden (1987, p. 302) mentioned the term "relational models" pointing to the work of van der Smagt (1985) and Hendriks (1986) in the field of the functional classification theory. In this relational modelling approach, the decision heuristics of the subject are related to the structural position of that subject. The position taken in this thesis is also that of an interrelated approach of actor and object; the actor referring 
to an entrepreneur, a decision-maker, a firm or a planner, the object referring to the environment or superstructure. As such, the approach not only emphasizes the importance of actor-specific behaviour, but also takes account of structural constraints. Establishing such an actor-object or "end-means" relationship has everything to do with a matching or classification problem. That is, a potential production environment, characterized by a variety of location factors, can only function as a suitable location site, if the characteristics of the production environment relationally match with the characteristics of the production requirements put forward by the firm.

\section{MODELLING SITE SUITABILITY IN LOCATION THEORY AND PLANNING}

Given the above specified definition of what is to be understood by "matching" - i.e. the direct linking of actor requirements with context attributes by means of a series of heuristic rules - it is now analyzed what kind of modelling implications such an approach brings with it. Although, in the location literature, several attempts have been made to actually model site suitability as a matching problem, in many of these approaches an actual modelling procedure has - with the exception of Reitsma (1990) — hardly ever been formalized. Nevertheless, two approaches deserve a special mention: first, there are a number of so-called "locational feasibility studies"; and second, there is Reitsma's (1990) approach of the functional classification of space.

Locational feasibility studies (e.g. US Department of Commerce, 1947; Schilling, 1968; Pellenbarg et al., 1974) advance a traditional matching approach to site suitability. This signifies that a careful matching of technology requirement profiles on the one hand with a regional profile on the other is examined. As such, a method of site suitability assessment is presented in which spatial production requirement profiles are matched with locational property profiles. These spatial production requirements of an industry are a function of the characteristics of its 
production process. For example, depending on the type and quantity of raw materials needed, specific forms of transportation and infrastructure are required. The production process, or in a more general term, the "technology" applied by the industry, also determines the quantity and quality of the employment. Note that an identical interpretation can be used for determining the energy and water requirements. Undoubtedly, the amount and types of spatial production requirements associated with specific production processes varies significantly. Therefore, different categories of industry need to be specified, each of which has a specific spatial requirement profile. In short, the method proposed in the locational feasibility studies offer several interesting elements in respect to an implementation of locational choice modelling based on a matching approach. They recognize to some extent the activity-specific nature of site suitability modelling and introduce non-compensatory elements. As a modelling procedure, however, it has some important disadvantages. For instance, no account is given to compensatory relations which exist among location factors. Moreover, activity types are often too rigidly defined, certain requirements are not properly quantified or not related to others, and the twoway matching of locational requirements and spatial production requirements is sometimes ignored.

The fact that the locational decision-making process should be modelled as a more than simple one-to-one matching problem was also recognized by R.F. Reitsma (1987, 1988, 1990). The point of departure of his approach is the methodological assumption that the definition and measurement of a theoretical concept such as "suitable location site" cannot solely be based on the empirical characteristics of locations or the empirical similarities of different location sites. Instead, site suitability should be regarded as "the result of a matching of the characteristics and interests of an activity (actor), and the properties of a location (object), as the same empirical properties and combinations of properties of locations, can fulfil very different roles for different activities" (Fedra and Reitsma, 1990, p. 183). Note that what is stressed in this approach is not to 
find an optimal location site, but a site that can under certain conditions fulfil a specific function for an economic activity. Therefore, this notion of functionality of location sites should be reflected in the modelling formalism.

In order to be able to functionally classify the surrounding space, Reitsma (1990, p. 7) suggested the use of a so-called "relational" matching approach. It can be regarded as a settheoretic representation of a concept such as site suitability, i.e. as a set of necessary and sufficient conditions in terms of functionally matching economic activity and locational properties and characteristics. The computerized matching process developed by Reitsma (1990), based on the modelling formalism of inference trees, comes down to a processing (or functional linking) of an activity-specific rule base with the data for a set of locations stored in a locational data base. The members of this locational data base are tested on the locational requirements inferred from the rule-base. After determining the location sites which will be matched, and after determining the exact characteristics of the activity, the matching programme processes the associated rule-base, collects the locational requirements, and checks the locations on these requirement (Reitsma, 1990, p. 139). The resultant model, designed to help generate different matching evaluations, was implemented in a separate knowledge-based system (KBS) called REPLACE (RElational Plant Location and Acquisition Enquiry). This KBS made up a separate module in a larger overall decision support system used to facilitate the reorganization of the regional economy in the province of Shanxi in the People Republic of China. In all, 107 potential location sites (i.e. different counties within the Shanxi province) were distinguished, each typified in terms of 49 basic, non-derived locational variables. The number of different economic activity types was rather limited; i.e. the locational analysis of the aluminum and aluminum processing industry was used as an example. Therefore, Reitsma (1990, p. 254) admitted that the examples only represented a mere starting point since the analysis needed to be significantly extended and improved. 
Based on the aforementioned methodological approaches to matching (locational feasability studies and the theory of functional classification of space) and the conducted survey of the current relevant location literature, four fundamental principles can be deduced which need to be fulfilled when applying a matching approach to define and model site suitability (Witlox, 1998). In particular, the proposed approach towards matching should (i) be based on the concept of functionality, (ii) allow for location factor variability, (iii) permit compensatory and noncompensatory rules, and (iv) be able to account for decision imprecision. These modelling characteristics will lead to what will be called a relational matching approach to site selection. Let us take a closer look at these four fundamental principles. 


\subsection{Matching approach based on functionality}

As argued in the previous subsections, the problem of locational site suitability will have to be defined and modelled as a matching process. It involves the direct confrontation of a requirement profile, generated by an economic activity, with a property profile, characterizing a potential location site. As such, an approach is advanced in which functional relationships between an activity and its environment are explicitly taken into account. This integrated view on locational decision-making recognizes the importance of behaviour-limiting structural constraints (structuralism) and also emphasizes the role of the individual actor or economic activity and its relation to and cognition of the environment (behaviouralism).

The fact that site suitability modelling implies conducting a matching analysis becomes even more evident when one tries to answer the following, seemingly straightforward question: "What is to be understood by a suitable location site?". Indisputably, the notion of site suitability will depend upon the kind of economic activity that is being analyzed. For example, it is clear that a location in the city centre may be exceptionally well-suited for establishing an insurance company, a retail business or a diamond-cutting factory, while it is an absolutely inappropriate location for a chemical company, an oil refinery or a car assembly plant. Although this assertion may seem straightforward, perhaps even self-evident, it is nevertheless of great significance. It implies that every economic activity generates or induces its own specific locational requirements, and - equally interesting — that each location site will attract or repel certain economic activities merely as a result of its intrinsic locational characteristics. In other words, a concept like "site suitability" is defined in terms of "end-means relationships". Only if a location site is able to fulfil or meet the imposed spatial requirements or objectives specified by an economic activity, can it be termed a suitable location site for that particular activity, and thus be classified accordingly. Therefore, the problem of locational site suitability modelling consists in 
trying to relationally match a set of conditions put forward by a given economic activity with a set of attributes that define potential location sites, or vice versa. Only when such a matching process yields a successful result, is site suitability achieved and the concept appropriately defined.

Note that in the current definition of matching, the aspect of functionality is stressed. It implies that location sites, although exhibiting different profiles, can be regarded as equally suitable if they are able to fulfil the economic activity's specified production requirements. It also implies that an appropriate matching modelling technique is required.

One of the main justifications to model site selection as a functional matching problem is that such an approach is able to account for the activity-specific nature of location factors. In addition, the approach is also able to deal with the issue of variable interrelatedness because it fully acknowledges the importance of location factor variability (be it context-dependent or internally dependent).

\subsection{Location factor variability}

The variability in the importance of location factors results from the existing heterogeneity in the economic activity types, and is also caused by the internal dependencies between different factors.

First, due to the differences in the actual organizational characteristics and spatial production requirements of different economic activities, location factors exhibit an activityspecific variation. In other words, different properties of a location site become important if different types of economic activities are assumed. This fact also implies that the definition of a concept like site suitability is activity-related: if the activity changes, the site selection problem changes as well. The issue of activity heterogeneity and dependency may cause a problem of 
generalization. Hence, the existence of the context-dependent variability in the (in)significance of location factors needs to be reflected in the modelling approach.

Second, and related to the activity-specific nature of location factors, is the issue of variable interrelatedness. It refers to the existence of internal dependencies between different location factors (whether or not viewed separately from the activity-dependent aspect). In particular, a distinction can be made between the changing relevancy of a location variable as a result of the presence or absence of other location factors (i.e. conditional relevance), and the change in (un)importance of a factor resulting from the fact that certain factors have or have not been assigned particular values (i.e. conceptual interaction). As such, the possibilities of internal relationships between location factors are not limited to the inter-dependence of categorizations of location factors, but the same holds for the (in)significance of complete location factors.

\subsection{Compensatory and non-compensatory decision-making}

The proposed matching model of site suitability will also have to provide means to incorporate both compensatory and non-compensatory relations (Timmermans, 1984). These relations originate from so-called location factor-specific effects which refer to a varying degree of importance of individual, separate location factors. For example, it might be the case that a specific location factor is deemed to be so decisive that all location site alternatives that do not meet the requirements imposed by this factor are automatically rejected. Such a location factor is said to be "non-compensatory", often also referred to as a rejection-inducing variable or a vetodimension. Although, site selection is an essentially non-compensatory decision-making process — if a certain requirement is not satisfied, the location is eliminated from further analysis — this does not imply that compensatory rules should be disregarded. While, in site selection, noncompensatory rules may be fine on a rather abstract level of general location factors, 
compensatory rules may account for more subtle evaluations between different lower level location variables. As such, both decision rules should be incorporated in the model.

One way of dealing with compensatory and non-compensatory decision-making is to make use of combined conjunctive ("AND") and disjunctive ("OR") model structures. The disjunctions, consisting of different conjunct sets of decision influencing attributes, may represent various ways in which an activity or locational requirement can be fulfilled.

\subsection{Flexibility and decision imprecision}

Given that the locational decision-making process is characterized by decision imprecision or fuzziness, and that it is our purpose to model this process by means of a matching approach, the modelling technique put forward will have to account for imprecision. In other words, what is needed is a flexible approach towards matching which is able to some extent to indicate the degree of imprecision associated with certain matching results. There are many different ways to deal with this issue. For instance, the availability of global matching parameters by which one can introduce a kind of tolerance factor into the measurements might be a potential solution. The introduction of sensitivity analysis, or the inclusion of (un)certainty assessments considering the significance of specific requirements or actor and objects attributes might be another.

It is interesting to note that Reitsma (1990, p. 76) has argued that this lack of incorporating uncertainty and imprecision in the matching process may well have contributed to a loss of interest in the approach as a modelling technique in the 1980s. However, Reitsma's own matching approach is also deterministic. Consequently, it is obvious that the very strict and deterministic character of the existing matching approaches is its principal weakness that has to be properly dealt with.

In sum, an approach to location theory should be advocated in which the site selection 
problem is defined and modelled as an integrated and functional, activity-specific, flexible matching approach which accounts for the complexity of a variety of influencing location factors, the problem of internally related variables, the issue of compensatory and noncompensatory choice making, as well as the existence of imprecision in locational decisionmaking.

\section{MODELLING A RELATIONAL MATCHING APPROACH}

At the heart of a relational modelling approach lies a matching principle. The general notion of matching so-called object-context relationships in locational choice modelling - a set of conditions put forward by a given economic activity with a set of attributes defining potential location sites - points to an approach that aims at modelling the concept of site suitability. In this respect, three model building aspects need to be more closely examined: (i) the context or the actors, referring to the economic activity type involved, (ii) the objects, pointing to potential location sites, and (iii) the relational matching mechanism, the outcome of which determines the degree of site suitability. 


\subsection{Knowing the actors}

When developing a model to represent the concept of "site suitability", the reconstruction of the object-type "suitable location site" is the first step. It typically involves the specification of a context for which the particular object-type needs to be specified. Conditional upon this context specification, the notion of site suitability can be defined. In the present study, the context consists of an actor which in turn refers to the type of economic activity that is being analyzed. It follows that only through the specification of this economic activity, the object-type "suitable location site" obtains its right contextual meaning. Also, in respect to defining location factors, reference should be made to the context. To illustrate, the meaning of a location variable like "availability of skilled labour" depends upon the type of labour required by the economic activity (Reitsma, 1990, p.45). McQuaid et al. (1996, p. 587) came to identical conclusions in respect to evaluating the influence of accessibility in location decisions.

It is a well-known fact that the context both imposes and has an influence on site selection (Reitsma, 1990). The active influence stems from the economic activity's imposed spatial production requirements on locational decision-making, while the passive (inherent) influence originates from the actor's organizational profile. To illustrate, a chemical company with a hazardous, possibly toxic and polluting production process will, given its spatial production requirements, explicitly demand a location site well outside a residential area for establishing its business (i.e. responsible care principle). Whereas, it is evident that, for the same chemical company, a location somewhere in the city centre cannot possibly be suitable, given the company's inherent corporate and organizational structure. Obviously, the actor's organizational profile and its spatial production requirements are very closely linked. Notwithstanding this fact, the consequence is that both influences (i.e. spatial production requirements as well as organizational characteristics) should be included in the collection of the context-related data, 
and made explicit in the choice model.

In this respect, there exists the problem of heterogeneity in the actual organizational characteristics and spatial production requirements of different types of economic activity, as well as the variation in strategies and objectives in these aspects by the same actor. The result is a diversity of actor profiles. The difficulty of dealing with activity-type heterogeneity implies finding a solution to the problem of how to handle, and more important, actually model the activity-specific nature of location factors. Due to the variations in economic activity types, the (in)significance of location factors is subject to changes. It goes without saying that the only appropriate solution to this important problem is to represent and incorporate the variation in activity types in the selected modelling approach.

Given that the selection of the actor usually sets the scene of the problem area under investigation, most approaches to modelling locational site selection are said to be actor or activity-driven. By this is meant that the economic activity will eventually determine whether a potential location site is considered suitable or not, and not the other way around. Note that this approach logically follows from the chosen research approach to model the concept of "site suitability" (and not "suitable economic activity", given a location). The matching process only calls for the search for suitable sites, given a specific activity, which of course implies a one-way approach to matching. However, as also mentioned above, a "true" relational match has a symmetrical structure; actors and objects on either side, and a relational model in the middle. Therefore, in theory at least, if one of the sides is initialized, and the relational model is known, it must be possible to deduce the result of the opposite side.

In the discussion thus far, it has been assumed that, once the individual actor is fixed, i.e., once the specific economic activity or context has been chosen, the resultant set of functionally equivalent locations can be determined. However, attention should also be paid to how demands generated by the objects should be dealt with, and what kind of implications this might have on 
the collection of the object-related data. In other words, given a specific location, how can the set of suitable economic activities for which this location can be regarded as appropriate, be deduced. Viewed in this way, an object-driven approach is followed by simply inverting the modelling problem.

\subsection{Knowing the objects}

Unlike the actors, the objects — pointing here to potential production environments or location sites — only seem to fulfil a passive role in site selection. This means that demands generated by the objects are assumed not to exert any influence on the stipulation of what might be considered a suitable economic activity for a particular location site. Instead, it is conjectured that different types of economic activities are simply attracted or opposed to a particular site, given the location's property profile. Nevertheless, to a certain degree, a location site is also able to exert an influence on the type of economic activity that will locate. These object requirements, i.e., the active influence of the object on site selection, should be considered a part of a two-way relational definition of a concept such as site suitability. Therefore, in addition to taking into account the characteristics of the object in the collection of the object-related data, the generated imposed requirements of the object, being the spatial implication of location sites, or better, of people and organizations with authority over these sites (i.e. specified regulations such as building and locational permits) should be included in the model as well. In this respect, a restrictive policy regulation can be considered an object demand. There are several sound arguments in favour of such an approach. For instance, when it comes down to actually making the decision as to where to locate an economic activity, it will be important to know whether certain restrictions such as locational permits or environmental regulations prevent an activity from locating on the selected site. If this is the case, the particular location cannot possibly be 
regarded a suitable choice alternative, and should therefore be excluded from the set of available location alternatives. Consequently, in order to be able to model the process of locational choice behaviour, object requirements have to be included in the data and in the model. The question which remains is, how these object demands can be fitted in our initial objective of modelling site suitability?

The object requirements can both be incorporated either in terms of "inverted" actor requirements, or through the stipulation of specific dimensions or attributes referring to these requirements. The former approach of masking the object demands as inverted actor requirements is advocated and applied by Hendriks (1986) and Reitsma (1990). It is achieved by formulating an actor requirement in such a way that it states that the object which is matched must not require anything the actor cannot fulfil. For instance, if it is stipulated in a regulation that on a particular location site no company is allowed to set up its business if it operates with or stores dangerous goods (i.e. an environmental locational requirement), this restriction can be reformulated as an actor requirement stating that all location sites that inhibit the establishment of potentially dangerous economic activities should be rejected from the set of functionally equivalent suitable location sites. In the second, more direct approach, dimensions or location factors such as environmental policy, water pollution guidelines, emission standards, safety measures, etc., which have to be observed and are to some extent determined by a specific location, contain requirements of locations in terms of locational regulations. Therefore, the process of identifying from the start which necessary conditions have to be satisfied by an economic activity prior to considering the location a suitable candidate for establishing the plant, is an important element in site selection.

Having identified the actors and the objects on either side, what remains is the discussion of the process of relational matching which aims at combining and confronting both actor and object profiles. 


\subsection{Knowing the matching mechanism}

The relational approach to location theory refers to a paradigm within which site selection is modelled as a relational matching problem. It is the process of relationally linking or confronting the economic activity profiles, which are defined in terms of a set of actor characteristics and requirements, with the locational property profiles, which are specified in terms of a set of object characteristics and demands.

The idea of approaching site selection as a matching problem is not new and different matching techniques exist. To formalize the matching problem, let $C=\left\{C_{1}, C_{2}, \ldots, C_{\mathrm{N}}\right\}$ be the set of conditions characteristic of a given economic activity, $A=\left\{A_{1}, A_{2}, \ldots, A_{\mathrm{N}}\right\}$ the set of attributes of a location relevant for that activity, and $m$ a judgement of the degree of match between the economic activity and the location alternative (Arentze et al., 1996, p. 3). Then, the modelling problem is to specify the set of rules that defines the relationship between these different elements. This relationship can be written in the conceptual modelling language PROLOG as follows:

match_judgement $(C, A, m)$

The judgement $m$ may be expressed in a number of ways. Frequently, performance scaling or a Likert-type of measurement scale is used to express the degree of (mis)match on each attribute level. For instance, if a three-point ordinal scale is applied, "0" might imply a perfect match, while "+1" indicates an over performance, and "-1" signifies an under performance. In the case of a so-called "perfect" (or satisfactory, suitable) matching result, it is found that an object's supplied dimension (i.e. a location factor characterizing a site) complies with the demanded 
requirement put forward by the actor (i.e. an economic activity), while the actor is also able to conform to the demands generated by the object. A perfect match will also be accomplished if the economic activity does not impose any requirements with respect to the dimension that is being examined. In the case of an under performance, the mismatch may be due to the fact that the spatial production requirements put forward by the actor are too strong compared to the locational property characteristics of the object(s). Stated differently, the objects are simply deemed too weak to be able to fulfil the actor's requirements. Conversely, although less of a problem and often dependent upon the model specification, an over performance may also be considered a mismatch. It implies that either the set of actor requirements is too weakly formulated, or the object is simply too well-suited (i.e. over qualified). To consider an over performance as a mismatch might be justified in that the economic activity is forced to pay extra, unnecessary costs for non-essential locational properties which offer no additional advantages to the locating company. Note that the use of a more elaborated, five-point (or even seven-point) scale, ranging from a (very) strong over performance to a (very) strong under performance, enables one to make more subtle and differentiated matching evaluations. An alternative, albeit less flexible measurement scale would be the use of a simple binary yes/no evaluation. With respect to the overall matching or performance outcome, this is usually obtained by applying some form of (compensatory) combination rule (e.g. a weighted sum over all attribute scores).

Although, the above matching approach may have some intuitive appeal, from the standpoint of relational matching, it is inappropriate for several reasons. First, the use of standard performance scales can be criticized for not being a "true" relational matching technique because relational matching implies more than simply evaluating a number of comparisons between different attribute-to-attribute confrontations. Moreover, it is not the (empirical) similarity between actor and object or between supplied versus demanded characteristic which is important, but rather the functionality between an activity and a location is essential. Therefore, 
locational site suitability can only be achieved if an economic activity's spatial requirements and characteristics functionally matches the locational property profile of a potential site. Second, a matching technique based on a one-to-one attribute comparison inhibits taking account of the interrelatedness between different attributes. As such, conditional relevance and conceptual interaction are being neglected which violates one of our stated matching fundamentals. Third and finally, the above-described matching approach also unavoidable relies on some form of compensatory decision-making since attributes are allowed to compensate one another when the overall degree of suitability or matching score is calculated. In this respect, the existence of a non-compensatory element is important because it illustrates, in the field of location theory, that specific sites will not be considered suitable if they lack certain characteristics which are required by the company. Hence, an alternative approach to modelling relationship [1] will have to be advanced. In this respect, we would like to advance the decision table approach. 


\subsection{Decision tables}

A decision table (DT) is a tabular representation used to describe and analyze procedural decision situations, where the state of a number of conditions jointly determines the execution of a set of actions. Not just any representation, however, but one in which all distinct situations are shown as columns in a table, such that every possible case is included in one and only one column (completeness and exclusivity). The tabular representation of the decision situation is characterized by the separation between conditions and actions, on one hand, and between subjects and conditional expressions (states), on the other. Every table column (decision column) indicates which actions should (or should not) be executed for a specific combination of condition states. In this definition, the DT concept is deliberately restricted to the single-hit table, where columns are mutually exclusive. Only this type of table allows easy checking for consistency and completeness (Vanthienen and Dries, 1994). A DT consists of four parts (Codasyl, 1982):

1. The condition subjects are the criteria that are relevant to the decision-making process. They represent the items about which information is needed to take the right decision. Condition subjects are found in the upper left part of the table.

2. The condition states are logical expressions determining the relevant sets of values for a given condition. Every condition has its set of condition states. Condition states are found at the upper right part of the table. 
3. The action subjects describe the results of the decision-making process. They are found in the lower left part of the table.

4. The action values are the possible values a given action can take. They are found at the lower right part of the table.

A DT is a function from the Cartesian product of the condition states to the Cartesian product of the action values, by which every condition combination is mapped into one (completeness) and only one (exclusivity) action configuration. If each column only contains simple states (no contractions or irrelevant conditions), the table is called an expanded DT. If necessary, columns in an expanded DT can be contracted. Contraction combines columns or groups of columns that only differ in the state value of one condition and that have equal action configurations into respectively one column. It is important to note that contraction does not change the knowledge contained in the DT. Only the format in which it is presented to the user is changed. Contraction is important in order to enhance the effectiveness of the decision-making or to provide a more compact formulation that can serve as a basis for discussion between the expert and the knowledge engineer.

\subsection{Decision tables as relational matching formalism}

In this section, we concentrate on the evaluation of the DT method as relational modelling formalism to analyze spatial choice problems. Serving as a guiding principle here, are the four relational model requirements that have been formulated in section 4.

First, given that end-means or condition-action relationships are directly being linked, DTs adopt an explicit approach towards matching. In other words, the direct, vertical linking of condition categories and action categories produces an "if...then" decision rule which is 
accomplished without having to make underlying or intermediate measurements of the different condition states. These logical decision heuristics are then represented or visualized in a humanoriented table structure which makes the DT a suitable instrument to model difficult choice procedures without running the risk of losing control or oversight. The decision rules also exhibit a logical structure of a disjunction of conjoint terms, hence fulfilling the property of functional equivalence and allowing to take account of internal related conditions. An additional advantage of DTs is that the formalism offers some means to partition a complex matching problem into a hierarchical structure of subtables, each of which can be considered a matching problem of its own. As such, the use of subtables enables one to divide a complex choice problem into smaller, more manageable problems.

Second, the definition of conditions, actions, condition states and action states can both be accomplished on an a priori and a posteriori basis. There are no restrictions imposed on the categorization of the condition and action states. However, more important, the automated and computer supported DT construction offers a number of advantages which may avoid specification errors in the definition of these choice influencing attributes. In this respect, the verification capacity of DTs automatically checks the table for the existence of (i) incompleteness and (ii) inconsistencies due to contradictions and redundancy in the problem specification.

Third, the conditions and condition states are not weighed. As such, a matching rule is not based on some form of algebraic decision rule which might entail a compensatory decisionmaking model. Instead, in a DT, a combination of compensatory and non-compensatory rules can be used. On the one hand, a DT allows for compensatory decision-making because when a first condition is evaluated as unfavourable and it is not rejection-inducing, it can be compensated by the satisfactory result of another condition. Hence, functional equivalent matching results can be obtained. On the other hand, the so-called dominant or veto conditions, 
usually placed at the top of the table, which induce the rejection of the alternative if they are not satisfied, could be viewed as non-compensatory.

Fourth, DTs are capable of taking into account the effects of the context. This follows from a matching approach in which the decision rules reflect the degree of match between the context (i.e. economic activities) and an object (i.e. location alternatives). Consequently, the resultant DT combines conditions referring to the context and the object. In such an end-means matching approach, the influence of the context is modelled from the start. Clearly, as the context changes, the matching result changes as well. Hence, DTs offer some means to represent the variation in activity types.

Thus far, the decision table formalism seems to provide an attractive framework for conducting relational matching operations. To paraphrase, it appears that its model characteristics "matches" very well the model requirements as put forward in previous chapters. However, an important potential drawback of the DT approach, like with all relational models, is its strict deterministic character. DTs do not have an error theory. As a result, they hide the imprecision that is often present in decision-making. The solution to this problem is to allow for fuzzy sets in the condition and action space of the DT (see Witlox, 1998).

Another important issue concerns the validity of DT approach. A basic question in this respect, as also pointed by Timmermans and van der Heijden (1987, p. 301), is whether respondents are able to report accurately on their decision-making process by means of a DT structure. In other words, are individuals capable of articulating the heuristic decision rules incorporated in a DT and can they execute the information-processing rules in a predeterminated sequence? In addition, there may exist the problem that individuals may mention too many attributes merely because they are aware of being observed; on the other hand, they may not name attributes that they consider self-evident. The problem here is that of "reactivity". How will the respondents react if asked to describe their choice process? Will they 
demonstrate an elaborate, detailed, and well-organized decision-making? Or will they exhibit a rather unconscious, indifferent, and diverse decision-making? To some extent, the use of subtables can help to structure a decision problem. However, the point is that a DT structure will have to be validated ex post by the respondents.

\section{CONCLUSIONS}

This article advocated the need for a relational view to location theory. The point of departure was a discerning appraisal of the usefulness of the existing location theory in respect to defining and modelling the concept of site suitability. Various approaches, such as the (neo)classical location theory, the behavioural approach and the structural approach to location theory were critically assessed. It was argued that these theories are in essence largely monocausal, and that an integrated approach to location theory, stressing the relevance of activity-specific behaviour and taking account of structural constraints, should be brought to the fore. Hence, both the importance of structural, supra-individual constraints on behaviour and the effects of actor-specific factors should be recognized. It was further argued that the application of such an integrated approach in location theory required a specific modelling approach. Based on the early conceptualizations made in a number of locational feasibility and matching studies, supplemented with more recent views on the functional classification of space, a so-called relational matching approach was advanced. The main fundamentals underlying such a matching approach were briefly outlined.

An important issue which remained was the choice of modelling formalism. For this purpose, the decision table approach was suggested. The conclusion that DTs are able to function as relational matching formalism was endorsed by the fact that DTs adopt an explicit approach towards matching end-means relationships such as the links between locational 
requirements on the one hand and a choice-maker's objectives and characteristics on the other. In addition, DTs systematically allow for conceptual interaction between and conditional relevance of conditions which are two important mechanisms underlying functional equivalence. DTs are also capable of deal with compensatory and non-compensatory decision rules.

However, a point which deserves more attention is the fact that conventional DTs are unable to adequately deal with decision imprecision or vagueness. Hence, a choice making process is forced upon the decision-maker that only appears to produce exact matching results because the imprecision is not made explicit. The result may be an inflexible, too hard decisionmaking process. In order to solve this problem, conventional DTs can be enhaunced by incorporating fuzzy elements. 
AREntZe, T.A., G.L. LuCARDie, H. OpPewAL and H.J.P. Timmermans (1996) "A functional decision table based approach to multi-attribute decision making". Working Paper (prepared for the $3^{\text {rd }}$ International Conference on Retailing and Consumer Services Science), Telfs/Buchen, Austria, 22-25 June, 1996.

BODDY, M.J. (1987) "Structural approaches to industrial location". In: W.F. LEVER Ed. (1987) Industrial Change in the United Kingdom. London, Longman, pp. 56-66.

CODASYL (1982) A Modern Appraisal of Decision Tables. Report of the Decision Table Task Group of the Conference on Data Systems Languages (CODASYL). New York, Association for Computing Machinery (ACM).

DICKEN, P. (1971) "Some aspects of the decision making behavior of business organization". Economic Geography. Vol. 47 (3), pp. 426-437.

FEDRA, K. and R.F. REITSMA (1990) "Decision support and geographical information systems". In: H.J. SCHOLTEN and J.C.H. STILLWELL Eds. (1990) Geographical Information Systems for Urban and Regional Planning. Dordrecht, Kluwer Academic Publishers, pp. 177-188.

Greenhut, M.L. (1956) Plant Location in Theory and in Practise. Chapel Hill, University of North Carolina Press.

HAMILTON, F.E.I. (1974) "A view of spatial behaviour, industrial organizations and decision-making". In: F.E.I. HAMILTON Ed. (1974) Spatial Perspectives on Industrial Organization and Decision-making. London, John Wiley, pp. 3-43.

HAMILTON, F.E.I. and G.J.R. Linge (1983) "Regional economies and industrial systems". In: F.E.I. HAMILTON and G.J.R. LINGE Eds. (1983) Spatial Analysis, Industry and the Industrial Environment. 3 Regional Economies and Industrial Systems. Chichester, John Wiley, pp. 1-39.

Healey, M.L. and B.W. ILbery (1990) Location and Change. Perspectives on Economic Geography. Oxford, Oxford University Press. 
HENDRIKS, P.H.J. (1986) De Relationele Definitie van Begrippen. Amsterdam and Nijmegen, Koninklijk

Nederlands Aardrijkskundig Genootschap — Geografisch en Planologisch Instituut Katholieke Universiteit Nijmegen, Nederlandse Geografische Studies 24, Ph.D. thesis.

ISARD, W. (1956) Location and Space Economy. Cambridge, MIT Press.

Johnston, R.J. (1986) Philosophy and Human Geography: An Introduction to Contemporary Approaches. London, Edward Arnold.

LAMBOOY, J.G. (1986) "Locational decisions and regional structure". In: J.H.P. PAELINCK Ed. (1986)

Human Behaviour in Geographical Space. Essays in Honour of Leo H. Klaassen. Aldershot, Gower Publishing Company, pp. 149-162.

LAUNHARDT, W. (1882) "Die Bestimmung des Zweckmässigsten Standortes einer gewerblichen Anlage". Zeitschrift des Vereins Deutscher Ingenieure. Vol. 26 (3), pp. 106-115.

MASSEY, D.B. (1973) "Towards a critique of industrial location". Antipode. Vol. 5 (3), pp. 33-40.

MCQUAID, R.W., S. LeITHAM and J.D. NELSON (1996) "Accessibility and location decisions in a peripheral region of Europe: a logit analysis". Regional Studies. Vol. 30 (6), pp. 579-588.

Pellenbarg, P.H., F. SchuUrmans and J. Wouters (1974) De Ontwikkelingsmogelijkheden van Medemblik: Proeve van een Feasibility Study. Groningen, Rijksuniversiteit Groningen, Geografisch Instituut Groningen.

RAWSTRON, E.M. (1958) "Three principles of industrial location". Transactions and Papers. Vol. 25 (1), pp. 135-142.

REITSMA, R.F. (1987) "Inferentiebomen: een techniek voor het modelleren van relationele beslisregels". SWIM. Vol. 2 (4), pp. 2-8.

REITSMA, R.F. (1988) "Relationeel modelleren van het produktiemilieu van typen bedrijvigheid". In: A.G.M. VAn DeR SMAGT and P.H.J. HendRIKS Eds. (1988) Methoden op een Keerpunt: Opstellen aangeboden aan prof. drs. P.J.W. Kouwe. Amsterdam and Nijmegen, Koninklijk Nederlands Aardrijkskundig Genootschap — Geografisch en Planologisch Instituut Katholieke Universiteit Nijmegen, Nederlandse Geografische Studies 77, pp. 82-105. 
REITSMA, R.F. (1990) Functional Classification of Space. Aspects of Site Suitability Assessment in a Decision Support Environment. Laxenburg, International Institute for Applied Systems Analysis (IIASA), Ph.D. thesis.

SCHILlING, H. (1968) Standortfaktoren für die Industrieansiedlung. Ein Katalog für die Regionale und Kommunale Entwicklungspolitik sowie die Standortwahl von Unternehmungen. Wien, Österreichisches Institut für Raumplanung, Veröffentlichung Nr. 27.

SMiTH, D.M. (1966) "A theoretical framework for geographical studies of industrial location". Economic Geography. Vol. 42 (2), pp. 95-113.

TIMMERMANS, H.J.P. (1984b) "Decision models for predicting preferences among multiattribute choice alternatives". In: G. BAHRENBERG, M. FISCHER and P. NIJKAMP Eds. (1984) Recent Developments in Spatial Data Analysis: Methodology, Measurement, Models. Aldershot and Brookfield, Gower, pp. 337354.

TIMMERMANS, H.J.P. and R.E.C.M. VAN DER HEIJDEN (1987) "Uncovering spatial decision-making processes: a decision net approach applied to recreation choice behaviour". Tijdschrift voor Economische en Sociale Geografie. Vol. LXXVIII (4), pp. 297-304.

TOWNROE, P.M. (1975) "Approaches to the study of industrial location". In: D.B. MASSEY and W.I. MORRISON Eds. (1975) Industrial Location: Alternative Frameworks. London, Centre for Environmental Studies. pp. 32-40.

US DePartment of COMMERCE (1947) Basic Industrial Location Factors. Guide for Evaluating an Area's Resources for Industrial Development. Washington (D.C.), Office of Domestic Commerce, Area Development Division, Industrial Series No. 74.

Van Der Smagt, A.G.M. (1985) Definiëren en Relateren in Sociaal Wetenschappelijk Onderzoek. Nijmegen, Geografisch Instituut Nijmegen, Ph.D. thesis.

VANTHIENEN, J. and E. DRIES (1994) "Illustration of a decision table tool for specifying and implementing knowledge based systems". International Journal on Artificial Intelligence Tools. Vol. 3 (2), pp. 267-288. 
Walmsley, D.J. and G.J. LeWIS (1993) People \& Environment. Behavioural Approaches in Human Geography (2 ${ }^{\text {nd }}$ Edition). Essex, Longman Scientific \& Technical.

Weber, A. (1909) Über den Standort der Industrien. Teil I: Reine Theorie des Standorts. Tübingen, Verlag J.C.B. Mohr. Translated by C.J. FRIEDRICH (1929) Alfred Weber's Theory of the Location of Industries. Chicago, University of Chicago Press.

Witlox, F. (1998) Modelling Site Selection: a relational matching approach based on fuzzy decision tables. Eindhoven, Technische Universiteit Eindhoven, Ph.D. thesis. 